\title{
HUBUNGAN KEBISINGAN DENGAN PERSEPSI MASYARAKAT DI RUANG RAWAT INAP RUMAH SAKIT KELAS A, KELAS B DAN KELAS C KOTA BANDUNG
}

\author{
Lili Mulyatna*, Deni Rusmaya, Deri Baehakhi
}

Program Studi Teknik Lingkungan, Universitas Pasundan

\begin{abstract}
Abstrak
Kebisingan di lingkungan rumah sakit merupakan suatu permasalahan yang cukup serius dan harus diperhatikan. Sesuai dengan fungsinya rumah sakit merupakan tempat untuk merawat orang yang sakit, maka lingkungan rumah sakit sangat membutuhkan suasana yang tenang, nyaman dan terbebas dari kebisingan. Usaha untuk menanggulangi kebisingan di rumah sakit dapat dilakukan dengan cara penanggulangan kebisingan pada sumbernya, jejak perambatannya serta pada penerimanya. Untuk mengetahui unsur-unsur tersebut maka dilakukan penelitian ini agar dapat mengetahui tingkat kenyamanan para pekerja maupun pasien berdasarkan kualitas tingkat kebisingan rumah sakit. Salah satu upaya untuk mengetahui tingkat kenyamanannya yang dilakukan adalah membuat kuisioner yang ditujukan kepada pasien, dokter, perawat serta karyawan. Dipilih tiga rumah sakit yaitu RSUP Hasan Sadikin, Rumah Sakit Advent Bandung dan Rumah Sakit Santo Yusup karena ketiga rumah sakit tersebut berdekatan dengan jalan raya, pasar dan pusat perbelanjaan lainnya. Hasil kuisioner menunjukan bahwa 53,84\% responden di Rumah Sakit Hasan Sadikin, 46,15\% responden di RumahSakit Advent Bandung dan 66,67\% responden di Rumah Sakit Santo Yusup merasakan kebisingan. Sumber bising yang paling besar dari RSHS dan RS Santo Yusup yaitu percakapan, sedangkan di RSAB sumber bising yang paling besar itu dari kendaraan bermotor karena dekat sekali dengan jalan raya. Di setiap Rumah Sakit didapat data berdasarkan responden bahwa kebisingan yang berlangsung tidak terjadi secara terus menerus dan ada pada saat-saat tertentu terutama pada jam besuk pasien. Dari persepsi para responden di ketiga rumah sakit tersebut, dapat disimpulkan bahwa setiap orang yang berada di rumah sakit baik itu dokter, perawat, karyawan maupun pasien mereka masih merasakan kebisingan, namun kebisingan tersebut terjadi pada saat-saat tertentu seperti pada saat jam besuk jadi intensitas kebisingannya tidak terus-menerus.
\end{abstract}

Kata kunci: Metode Statistik Deskriptif, Rumah Sakit, Tingkat Kebisingan

\section{Pendahuluan}

Kebisingan adalah bunyi atau suara yang tidak dikehendaki dan dapat mengganggu kesehatan, kenyamanan serta dapat menimbulkan ketulian (Ukru, Tongkukut, \& Ferdy, 2016). Menanggulangi kebisingan merupakan salah

\footnotetext{
${ }^{*}$ Penulis Korespondensi:

E-mail: lili.mulyatna@gmail.com

Diterima pertama kali: 30 Januari 2017

Direvisi : 2 Maret 2017

Disetujui untuk publikasi: 3 Juli 2017
}

satu kegiatan atau program kesehatan lingkungan. Rumah sakit merupakan salah satu lembaga dimana terdapat dua kelompok populasi, yaitu orang sakit dan orang yang sehat (yang merawat orang sakit). Fungsi rumah sakit adalah merawat orang yang sakit dan mencoba menyembuhkannya sedapat mungkin, kegiatan rumah sakit antara lain rawat jalan, rawat inap, rawat gawat darurat, pelayanan medik, pelayanan penunjang medik, dan yang lainnya. Maka dari itu pengaturan dan tata letak ruangan dalam gedung beserta isinya harus sesuai dengan 
berbagai keperluan agar fungsi rumah sakit dapat berjalan dengan lancar sehingga kamar dan ruangan yang memerlukan susana tenang terhindar dari kebisingan (Depkes, 2004 ).

Kebisingan di lingkungan rumah sakit merupakan suatu permasalahan yang cukup serius dan harus diperhatikan. Sesuai dengan fungsinya rumah sakit merupakan tempat untuk merawat orang yang sakit, maka lingkungan rumah sakit sangat membutuhkan suasana yang tenang, nyaman dan terbebas dari kebisingan. Usaha untuk menanggulangi kebisingan di rumah sakit dapat dilakukan dengan cara penanggulangan kebisingan pada sumbernya, jejak perambatannya serta pada penerimanya. Untuk mengetahui unsur-unsur tersebut maka dilakukan penelitian ini agar memperoleh tingkat kenyamanan para pekerja maupun pasien berdasarkan tingkat kebisingan rumah sakit.

\section{Metodologi Penelitian}

\section{Lokasi Penelitian}

Lokasi penelitian adalah Rumah Sakit Hasan Sadikin (RSHS), Rumah Sakit Advent, dan Rumah Sakit Santo Yusup. Tabel 1 memperlihatkan ruang rawat Kelas I, II dan III yang menjadi lokasi sampling di masing-masing rumah sakit.

Tabel 1. Ruang sebagai Titik Sampling

\begin{tabular}{cccc}
\hline Rumah Sakit & Kelas & Kelas & Kelas \\
& $\mathbf{1}$ & $\mathbf{2}$ & $\mathbf{3}$ \\
\hline Hasan & Fresia & Fresia & Kana A \\
Sadikin & 3.2 .04 & 1.2 .14 & 6 \\
\hline Advent & Ruang & Ruang & Ruang \\
Bandung & 443 & 449 & 430 \\
\hline Santo Yusup & Lukas & Lukas & Cosmas \\
& 4 & 6 & $8-9$ \\
\hline
\end{tabular}

\section{Pengambilan Data Kuisioner}

Pengambian data kusioner dilakukan dengan menggunakan metode sampling, dimana data yang digunakan adalah cara sampel proportionate stratified random. Cara ini digunakan bila anggota/unsur yang tidak homogen dan berstrata secara proporsional serta respondennya pun bersifat acak. Tabel 2 mempelihatkan populasi setiap titik sampling.

Tabel 2. Populasi Setiap Titik Sampling

\begin{tabular}{ccccc}
\hline $\begin{array}{c}\text { Rumah } \\
\text { Sakit }\end{array}$ & Pasien & Dokter & Perawat & $\begin{array}{c}\text { Paramedis/ } \\
\text { Karyawan }\end{array}$ \\
\hline RSHS & 10 & 8 & 18 & 8 \\
Advent & 14 & 8 & 14 & 8 \\
Santo & 10 & 6 & 12 & 6 \\
Yusup & & & & \\
\hline
\end{tabular}

Untuk mendapatkan data yang valid maka jumlah sampel yang dijadikan responden yaitu 50\%.Hal ini karena jumlah populasi tidak terlalu banyak. Untuk mendapat jawaban yang lebih meyakinkan jumlah responden dilebihkan 1 orang sehingga didapat jumlah responden seperti terlihat pada Tabel 3.

Tabel 3. Jumlah Responden tiap Rumah Sakit

\begin{tabular}{ccccc}
\hline $\begin{array}{c}\text { Rumah } \\
\text { Sakit }\end{array}$ & Pasien & Dokter & Perawat & $\begin{array}{c}\text { Paramedis/ } \\
\text { Karyawan }\end{array}$ \\
\hline RSHS & 6 & 5 & 10 & 5 \\
Advent & 8 & 5 & 8 & 5 \\
Santo & 6 & 4 & 7 & 4 \\
Yusup & & & & \\
\hline
\end{tabular}

\section{Hasil dan Pembahasan}

Waktu Sampling

Waktu pengambilan kuisioner di Rumah Sakit Hasan Sadikin yaitu pada hari Selasa-Rabu tanggal 15-16 Maret 2016, Rumah Sakit Advent Bandung pada hari Rabu-Kamis tanggal 30-31 Maret 2016 dan Rumah Sakit Santo Yusup yaitu pada hari Kamis-Jum'at tanggal 3-4 Maret 2016.

\section{Hasil dan Pembahasan di Rumah Sakit Hasan Sadikin Bandung \\ Hasil dari pengambilan kuisioner dari Rumah Sakit Hasan Sadikin beserta pembahasannya dapat dilihat pada Tabel 4.}


Tabel 4. Hasil Perhitungan Kuisioner Rumah Sakit Hasan Sadikin Bandung

\begin{tabular}{|c|c|c|}
\hline Pertanyaan & Jml & $\%$ \\
\hline \multicolumn{3}{|c|}{ I. Responden berdasarkan status } \\
\hline a. Dokter & 5 & 19,23 \\
\hline b. Perawat & 10 & 38,27 \\
\hline c. Paramedis / Karyawan & 5 & 19,23 \\
\hline d. Pasien & 6 & 23,07 \\
\hline
\end{tabular}

II.Responden berdasarkan jenis kelamin :

apakah anda seorang?

\begin{tabular}{llll} 
a. Pria & & 10 & 38,47 \\
b. Wanita & & 16 & 61,54 \\
\hline III. & Responden berdasarkan & usia & $:$ \\
berapakah usia anda? & & & \\
a. $15-20$ tahun & & \\
b. 20-30 tahun & 15 & 57,68 \\
c. $30-40$ tahun & 10 & 38,47 \\
d. $40-50$ tahun & 1 & 3,85 \\
e. $>50$ tahun & & \\
\hline
\end{tabular}

1. Selama anda bekerja/dirawat di rumah sakit, apakah anda pernah merasakan kebisingan?
a. Ya
$14 \quad 53,84$
b. Tidak
$12 \quad 46,16$

2. Jika jawaban anda Ya/Kadang -

kadang, darimanakah sumber bising

itu berasal? (jawaban boleh lebih

dari 1)

a. Kendaraan bermotor

b. Percakapan $17 \quad 65,38$

c. Suara alat medis

d. Suara mesin/pompa air

$5 \quad 19,23$

e. Suara orang hilir mudik

$8 \quad 30,77$

f. Lain - lain

1142,31

$2 \quad 7,69$

3. Pada jam berapa kira - kira anda merasakan kebisingan? (jawaban boleh lebih dari 1)
a. $07.00-10.00$
1246,16
b. $10.00-13.00$
1246,16
c. $13.00-15.00$
$7 \quad 26,92$
d. $15.00-18.00$
$10 \quad 38,27$
e. $18.00-21.00$
15,38
f. $>21.00$
$2 \quad 7,69$

4. Menurut anda, bagaimanakah tingkat kebisingan yang terjadi di

\begin{tabular}{|c|c|c|c|}
\hline & Pertanyaan & Jml & $\%$ \\
\hline & \multicolumn{3}{|l|}{ rumah sakit ini? } \\
\hline & a. Sangat tinggi & 2 & 7,69 \\
\hline & b. Tinggi & 8 & 30,77 \\
\hline & c. Biasa & 16 & 61,54 \\
\hline & \multicolumn{3}{|l|}{ d. Rendah } \\
\hline & \multicolumn{3}{|l|}{ e. Sangat rendah } \\
\hline \multirow[t]{10}{*}{5.} & Bagaimanakah pengaruh kebisingan & & \\
\hline & terhadap kegiatan anda jika anda & & \\
\hline & seorang dokter, perawat, paramedis, & & \\
\hline & karyawan / pengaruh kebisingan & & \\
\hline & pada proses penyembuhan anda jika & & \\
\hline & anda seorang pasien rawat & & \\
\hline & inap/rawat jalan? & & \\
\hline & a. Sangat menggangu & 8 & 30,77 \\
\hline & b. Kadang - kadang menggangu & 17 & 65,38 \\
\hline & c. Tidak menggangu & 1 & 3,85 \\
\hline \multirow[t]{11}{*}{6.} & Jika jawaban anda mengganggu / & & \\
\hline & kadang mengganggu, sampai & & \\
\hline & seberapa jauh tingkat kebisingan & & \\
\hline & tersebut mengganggu / apa yang & & \\
\hline & anda rasakan? & & \\
\hline & a. Sampai tidur pasien terbangun & 3 & 11,53 \\
\hline & b. Hanya sebatas nyaman / tidak & 13 & 50 \\
\hline & merasa nyaman & & \\
\hline & c. Dapat menghilangkan konsentrasi & 10 & 38,27 \\
\hline & kerja & & \\
\hline & d. Lain - lain & & \\
\hline \multirow[t]{6}{*}{7.} & Bagaimanakah kebisingan tersebut & & \\
\hline & berlangsung? & & \\
\hline & a. Terus menerus & 3 & 11,53 \\
\hline & b. Pada saat jam besuk saja & 10 & 38,27 \\
\hline & c. Diluar jam besuk & 4 & 15,38 \\
\hline & d. Pada saat tertentu & 9 & 34,82 \\
\hline
\end{tabular}

Tabel di atas merupakan data kuisioner yang diberikan kepada 26 responden terdiri dari 6 pasien, 5 dokter, 10 perawat dan 5 karyawan sebanyak 14 orang atau sebesar 53,84\% merasakan kebisingan dan 12 orang atau 46,16\% kadang merasa kebisingan. Berdasarkan sumber bisingnya paling banyak menyatakan berasal dari percakapan, suara orang hilir mudik, suara mesin/pompa, suara alat medis dan lain-lain (kursi roda, roda makan, dll). Sebanyak 46,16\% responden pada jam 07.00-10.00 dan 10.00- 
13.00 serta $38,27 \%$ responden pada jam 15.00 18.00 tingkat kebisingan yang dirasakan cukup tinggi. Walaupun demikian tingkat kebisingan yang terjadi di rumah sakit sebanyak $61,4 \%$ merasa biasa saja dan sebanyak $30,77 \%$ merasa kebisingannya tinggi. Pengaruh kebisingan terhadap kegiatan rumah sakit/proses penyembuhan pasien sebanyak $30,77 \%$ responden merasa terganggu dan sebanyak $50 \%$ responden merasa hanya sebatas kenyamanan saja. Sebanyak 38,27\% responden merasakan kebisingan pada saat jam besuk saja dan $34,82 \%$ responden merasakan kebisingan pada saat tertentu, artinya kebisingan di rumah sakit tidak berlangsung secara terus menerus/ kebisingan sesaat.

\section{Hasil dan Pembahasan di Rumah Sakit Advent Bandung}

Hasil dari pengambilan kuisioner dari Rumah Sakit Adventbeserta pembahasannya dapat dilihat pada Tabel 5 .

Tabel 5. Hasil PerhitunganKuisioner Rumah Sakit Advent Bandung

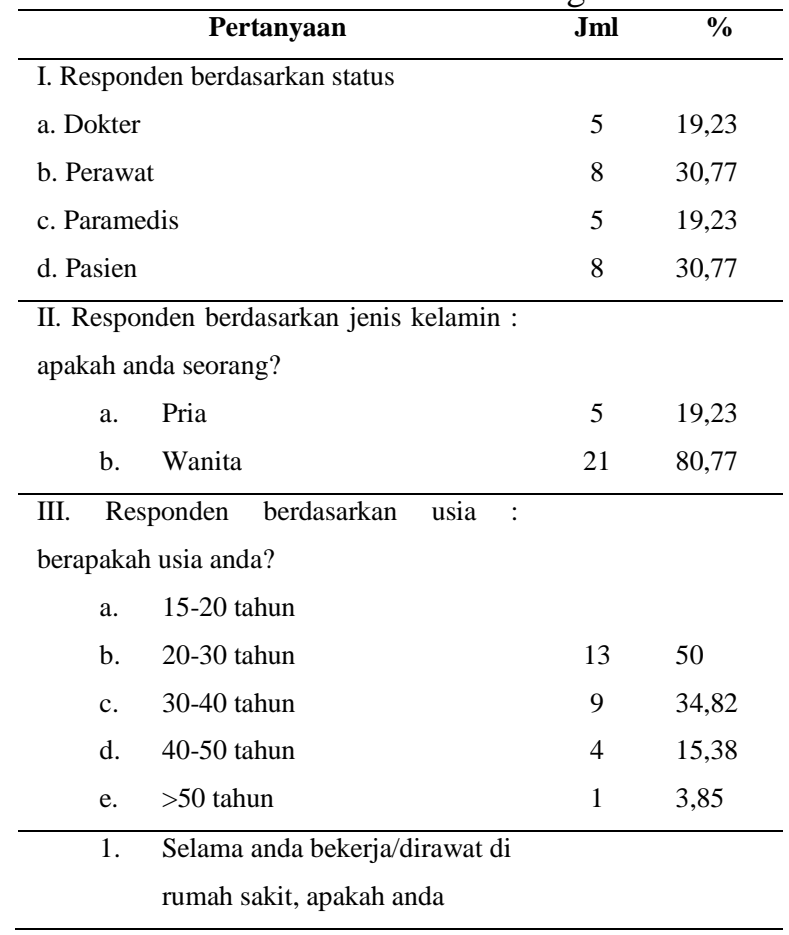

\begin{tabular}{|c|c|c|}
\hline Pertanyaan & $\mathbf{J m l}$ & $\%$ \\
\hline \multicolumn{3}{|l|}{ pernah merasakan kebisingan? } \\
\hline a. Ya & 12 & 46,15 \\
\hline b. Tidak & 1 & 3,85 \\
\hline c. Kadang - kadang & 13 & 50 \\
\hline \multicolumn{3}{|l|}{ 2. Jika jawaban anda Ya/Kadang } \\
\hline \multicolumn{3}{|l|}{ - kadang, darimanakah sumber } \\
\hline \multicolumn{3}{|l|}{ bising itu berasal? (jawaban } \\
\hline \multicolumn{3}{|l|}{ boleh lebih dari 1) } \\
\hline a. Kendaraan bermotor & 15 & 57,68 \\
\hline b. Percakapan & 11 & 42,31 \\
\hline c. Suara alat medis & 5 & 19,23 \\
\hline d. Suara mesin/pompa air & 3 & 11,53 \\
\hline e. Suara orang hilir mudik & 9 & 34,82 \\
\hline f. Lain - lain & 1 & 3,85 \\
\hline \multicolumn{3}{|l|}{ 3. $\quad$ Pada jam berapa kira - kira } \\
\hline \multicolumn{3}{|l|}{ anda merasakan kebisingan? } \\
\hline \multicolumn{3}{|l|}{ (jawaban boleh lebih dari 1) } \\
\hline a. $07.00-10.00$ & 4 & 15,38 \\
\hline b. $10.00-13.00$ & 12 & 46,16 \\
\hline c. $13.00-15.00$ & 6 & 23,07 \\
\hline d. $15.00-18.00$ & 10 & 38,27 \\
\hline e. $18.00-21.00$ & 1 & 3,85 \\
\hline f. $>21.00$ & 5 & 19,23 \\
\hline $\begin{array}{ll}\text { 4. } & \text { Menurut anda, bagaimanakah } \\
\text { tingkat kebisingan yang terjadi } \\
\text { di rumah sakit ini? }\end{array}$ & & \\
\hline a. Sangat tinggi & 1 & 3,85 \\
\hline b. Tinggi & 12 & 46,16 \\
\hline c. Biasa & 8 & 30,77 \\
\hline d. Rendah & 4 & 15,38 \\
\hline e. Sangat rendah & 1 & 3,85 \\
\hline \multicolumn{3}{|l|}{ 5. Bagaimanakah pengaruh } \\
\hline \multicolumn{3}{|l|}{ kebisingan terhadap kegiatan } \\
\hline \multicolumn{3}{|l|}{ anda jika anda seorang dokter, } \\
\hline \multicolumn{3}{|l|}{ perawat, paramedis, karyawan / } \\
\hline \multicolumn{3}{|l|}{ pengaruh kebisingan pada } \\
\hline \multicolumn{3}{|l|}{ proses penyembuhan anda jika } \\
\hline \multicolumn{3}{|l|}{ anda seorang pasien rawat } \\
\hline \multicolumn{3}{|l|}{ inap/rawat jalan? } \\
\hline a. Sangat menggangu & 11 & 42,31 \\
\hline b. Kadang - kadang menggangu & 11 & 42,31 \\
\hline c. Tidak menggangu & 4 & 15,38 \\
\hline
\end{tabular}




\begin{tabular}{lcc}
\hline \multicolumn{1}{c}{ Pertanyaan } & Jml & \% \\
\hline 6. $\quad$ Jika jawaban anda mengganggu \\
/ kadang mengganggu, sampai & & \\
$\quad$ seberapa jauh tingkat & & \\
$\quad$ kebisingan tersebut & & \\
$\quad$ mengganggu / apa yang anda & & \\
$\quad$ rasakan? & 8 & 30,77 \\
a. Sampai tidur pasien terbangun & 13 & 50 \\
b. Hanya sebatas nyaman / tidak & & \\
merasa nyaman & & 19,23 \\
c. Dapat menghilangkan konsentrasi & 5 & \\
kerja & & \\
d. Lain - lain & & \\
7. $\quad$ Bagaimanakah kebisingan & & \\
$\quad$ tersebut berlangsung? & & 3,85 \\
a. Terus menerus & 1 & 26,92 \\
b. Pada saat jam besuk saja & 7 & 65,38 \\
c. Diluar jam besuk & 17 \\
d. Pada saat tertentu & & \\
\hline
\end{tabular}

Tabel di atas merupakan data kuisioner yang diberikan kepada 26 responden terdiri dari 8 pasien, 5 dokter, 8 perawat dan 5 karyawan sebanyak 12 orang atau sebesar $46,15 \%$ merasakan kebisingan dan 13 orang atau 50\% kadang merasa kebisingan. Berdasarkan sumber bisingnya paling banyak menyatakan berasal dari kendaraan bermotor, percakapan, suara orang hilir mudik, suara mesin/pompa, suara alat medis dan lain-lain (kursi roda, roda makan, dll). Sebanyak 46,6\% responden pada jam 10.0013.00 serta $38,27 \%$ responden pada jam 15.00 18.00 tingkat kebisingan yang dirasakan cukup tinggi. Dengan demikian tingkat kebisingan yang terjadi di rumah sakit sebanyak 46,16\% merasa tinggi tingkat kebisingannya dan sebanyak 30,77\% merasa biasa saja. Pengaruh kebisingan terhadap kegiatan rumah sakit/proses penyembuhan pasien sebanyak $42,31 \%$ responden merasa terganggu dan merasa kadang-kadang terganggu. Sebanyak 50\% responden merasa hanya sebatas kenyamanan saja. Sebanyak 26,92\% responden merasakan kebisingan pada saat jam besuk saja dan $65,38 \%$ responden merasakan kebisingan pada saat tertentu, artinya kebisingan di rumah sakit tidak berlangsung secara terus menerus/ kebisingan sesaat.

\section{Hasil dan Pembahasan di Rumah Sakit Santo Yusup Bandung}

Hasil dari pengambilan kuisioner dari Rumah Sakit Santo Yusupbeserta pembahasannya dapat dilihat pada Tabel 5.

Tabel 5. Hasil PerhitunganKuisioner Rumah

\begin{tabular}{lcc}
\multicolumn{3}{c}{ Sakit Santo Yusup Bandung } \\
\hline \multicolumn{1}{c}{ Pertanyaan } & Jml & $\%$ \\
\hline I. Responden berdasarkan status & & \\
a. Dokter & 4 & 19,04 \\
b. Perawat & 6 & 28,58 \\
c. Paramedis & 5 & 23,8 \\
d. Pasien & 6 & 28,58 \\
\hline II. Responden berdasarkan jenis kelamin : & & \\
apakah anda seorang? &
\end{tabular}

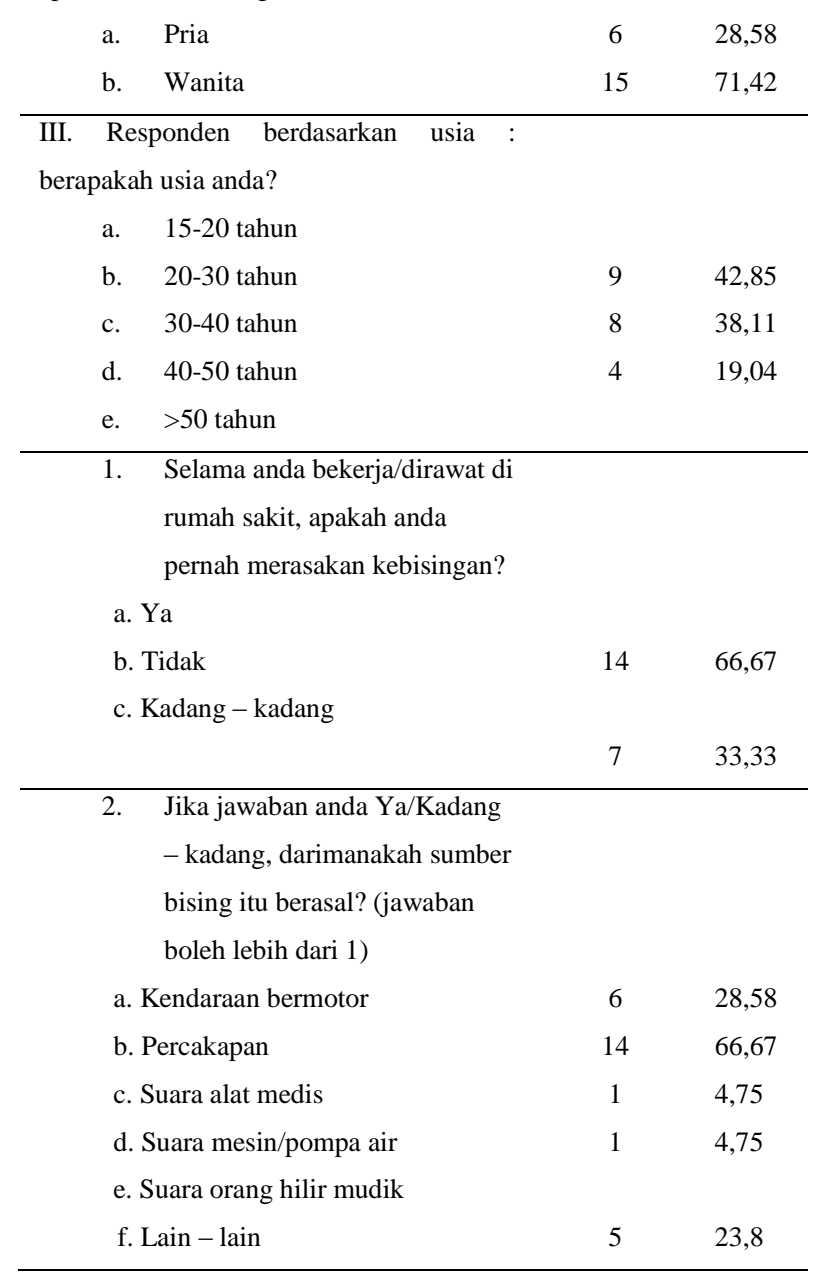


Journal of Community Based Environmental Engineering and Management, Vol. 1, No. 1: 25-31

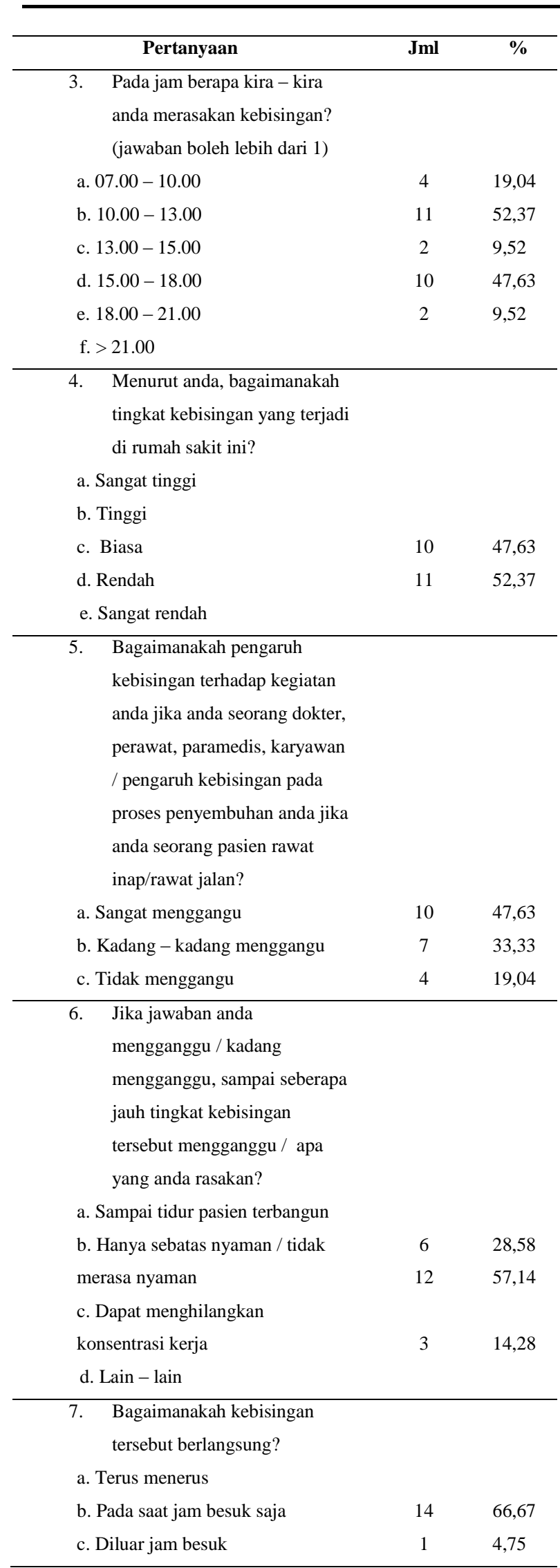

\begin{tabular}{rcc}
\hline Pertanyaan & Jml & $\%$ \\
\hline d. Pada saat tertentu & 6 & 28,58 \\
\hline
\end{tabular}

Tabel di atas merupakan data kuisioner yang diberikan kepada 21 responden terdiri dari 6 pasien, 4 dokter, 6 perawat dan 5 karyawan sebanyak 14 orang atau sebesar $66,67 \%$ merasakan kebisingan dan 7 orang atau 33,33\% kadang merasa kebisingan. Berdasarkan sumber bisingnya paling banyak menyatakan berasal dari percakapan, kendaraan bermotor, suara orang hilir mudik, suara mesin/pompa, suara alat medis dan lain-lain (kursi roda, roda makan, dll). Sebanyak 52,37\% responden pada jam 10.0013.00 serta $47,63 \%$ responden pada jam 15.00 18.00 tingkat kebisingan yang dirasakan cukup tinggi. Walaupun demikian tingkat kebisingan yang terjadi di rumah sakit sebanyak 52,37\% merasa biasa saja dan sebanyak $47,63 \%$ merasa kebisingannya tinggi. Pengaruh kebisingan terhadap kegiatan rumah sakit/proses penyembuhan pasien sebanyak $47,63 \%$ responden merasa terganggu dan sebanyak $57,14 \%$ responden merasa hanya sebatas kenyamanan saja. Sebanyak $66,67 \%$ responden merasakan kebisingan pada saat jam besuk saja dan 28,58\% responden merasakan kebisingan pada saat tertentu, artinya kebisingan di rumah sakit tidak berlangsung secara terus menerus/ kebisingan sesaat.

Diperoleh bahwa kebisingan akibat percakapan merupakan salah satu sumber kebisingan yang mengganggu. Kebisingan ini diakibatkan oleh aktivitas manusia di beberapa tempat di rumah sakit. Kondisi ini didukung oleh penelitian terdahulu yang menyatakan bahwa tingkat kebisingan akibat aktivitas manusia di rumah sakit sering melebihi ambang batas (Suryanti, Nurhasanah, \& Ihwan, 2014).

\section{Kesimpulan}

Berdasarkan hasil perhitungan kuisioner yang telah dilakukan pada setiap rumah sakit dapat disimpulkan : 
- 53,84\% responden di titik samplingRumah Sakit Hasan Sadikin, 46,15\% responden di Rumah Sakit Advent Bandung dan 66,67\% responden di Rumah Sakit Santo Yusup merasakan kebisingan.

- Sumber bising yang paling besar di titik sampling dari RSHS dan RS Santo Yusup yaitu percakapan, baik itu percakapan di sekitar pengambilan sampel maupun yang berasal dari luar, sedangkan di RSAB sumber bising yang paling besar itu dari kendaraan bermotor karena dekat sekali dengan jalan raya.

- Sebagian besar dari responden di titik sampling setiap Rumah Sakit merasakan kebisingan antara pukul 10.00-13.00 dan 15.00-18.00, yang biasanya pada jam tersebut terdapat jam besuk pasien serta kunjungan dokter.

- Sebagian besar responden di titik sampling RSHS dan RS Santo yusup merasa tingkat kebisingannya masih biasa saja, sedangkan di RSAB banyak responden yang merasa tingkat kebisingannya tinggi.

- Ada responden yang terganggu dan ada pula yang kadang merasa terganggu namun ratarata hanya sebatas tidak nyaman saja.

- Di setiap Rumah Sakit didapat data berdasarkan responden di titik sampling bahwa kebisingan yang berlangsung tidak terjadi secara terus menerus dan ada pada saat-saat tertentu terutama pada jam besuk pasien.

- Dari persepsi para responden di titik sampling ketiga Rumah Sakit tersebut, dapat disimpulkan bahwa setiap orang yang berada di rumah sakit baik itu Dokter, Perawat, Karyawan maupun Pasien mereka masih merasakan kebisingan, namun kebisingan tersebut terjadi pada saat-saat tertentu seperti pada saat jam besuk jadi intensitas kebisingannya tidak terus menerus.Meskipun demikian kebisingan tersebut harus dapat diantisipasi oleh setiap rumah sakit karena tingkat kebisingannya cukup tinggi.

\section{Daftar Pustaka}

Depkes. (2004). Departemen Kesehatan Republik Indonesia Direktorat Jenderal Pemberantasan Penyakit Menular dan Penyehatan Lingkungan. Persyaratan Kesehatan Lingkungan Rumah Sakit. Bandung: Departemen Kesehatan.

Suryanti, N., Nurhasanah, \& Ihwan, A. (2014). Tingkat Kebisingan akibat Aktivitas Manusia di Ruang Rawat Inap Rumah Sakit . Prisma Fisika, Vol 2, No. 2 , 49-54.

Ukru, S. L., Tongkukut, S. H., \& Ferdy. (2016). Kebisingan di Rumah Sakit Siloam Manado Sebagai Fungsi Jumlah Kendaraan yang Melewati Jl. Sam Ratulangi Manado. Jurnal MIPA Unsrat Online (2) , 95-98. 